\title{
How School Assimilation Lead to Unfair Treatment for Career Women
}

\author{
Shiyue $\mathrm{Li}^{1 *}{ }^{*}$, Yitong Zhou ${ }^{2, \dagger}$ \\ ${ }^{1}$ Foreign Language Institution, Shanghai Maritime University, Shanghai, 200000; China \\ ${ }^{2}$ Foreign Language Institution, Huzhou University, Wenzhou, 325000, China \\ ${ }^{*}$ Corresponding author. Email: ${ }^{1} 201810810165 @$ stu.shmtu.edu.cn \\ ${ }^{\dagger}$ These authors contributed equally
}

\begin{abstract}
Although gender discrimination is a well-known issue in workplace, research on educational assimilation and the impact of discrimination on career women is limited. The goal of this paper is to investigate whether educational assimilation has affected with gender discrimination in workplace and the path it affected. Based on current systematic review, this paper explained the definition, origin of educational assimilation which is caused by the less experience of institutions and blind pursuit of the similarity of key schools. Meanwhile, it analyzed three affects on students. Finally, this paper discussed gender discrimination, and analyzed the impact on career women in detail. According to the result, it ensures that there is close relationship between educational assimilation and gender discrimination. The paper ends with different types of the connection, with both pros and cons. These results shed light on how the gender separation in education influence unequal treatment of different gender in their workplace.
\end{abstract}

Keywords: educational assimilation, gender discrimination, career women

\section{INTRODUCTION}

With the progress of economy and technology, education receives increasing attention. Since the implementation of higher education expansion in 1999, the number of colleges and universities in China has increased rapidly, and the speed of higher education popularization in China is much higher than that in many developed countries [1]. This rapid development is mainly attributed to the advanced experience that is learned from Western developed countries [2]. However, due to China domestic educational policies that highlight the universal access to higher education, a large number of universities blindly expand the scale, resulting in the loss of their own characteristics and causing the formation of higher education assimilation.

Assimilation in higher education is regarded as an inevitable stage in the process of higher education popularization, which is also a frequent problem in China [3]. The assimilation of higher education embodies in two areas. The first area refers to the assimilation among schools, which consists of the convergence of orientation, training objectives and curriculum system of colleges and universities [4]. The second area is the convergence of thinking pattern that students restrict their discernment on what students should learn, especially on gender issues.

Meanwhile, gender discrimination in labor market has become a major concern. Plenty of studies have proved the disadvantaged position of women in the workplace from different angles, which embodied in the overall wage gap between men and women, less pay for women in the same work, and the difficult promotion for women $[5,6]$. Researchers also illustrate that fertility, social stereotypes and insecure workplace mechanisms for women are at the root of this weakness [7, 8]. On the other hand, women's low education level, which is affected by traditional stereotypes, is also an important factor leading to women's low competitiveness in the workplace. Although more females have gained access to higher education because of education popularization, the assimilation has also affected career women to some extent.

Accordingly, plenty of research suggested education should compensate for the disadvantages women face in the workplace [9]. Nevertheless, few scholars have 
focused on the impact of the educational environment on career women. The research about exploring the impact of assimilation in higher education on career women have been even more limited.

Assimilation is double-edged and, therefore, it is necessary to investigate the effect of higher education assimilation on career women. On the one hand, it has greatly increased the number of women receiving higher education, making women more competitive in the workplace. On the other hand, it has also damaged the structure of supplying and demanding in the job market in a degree, which is more difficult for individual woman to find a job.

Hence, the purpose of this paper is to study whether education assimilation caused career women's unfair treatment and how this higher education assimilation influence Chinese career women. On this basis, the paper analyzes the difficulties women may face in the workplace under the perspective of higher education, and tries to find the effective methods to solve the unfair treatment problem on career women in China.

\section{EDUCATIONAL ASSIMILATION}

\subsection{Definition}

Wordnet defines assimilation as the process of assimilating one cultural group and bringing it into harmony with another. In this process, the two cultures, as well as the way of thinking, values and self-positioning contained in the culture will tend to be the same. Assimilation of higher education has two meanings in this paper. First, it refers to the reinforcement of social stereotypes that apply to higher education, which has a convergent effect on students.

Social stereotype is a kind of prejudgment toward people or events. It can reduce people's cognitive burden, but at the same time, it can cause inertia and prejudice [7]. For example, women are often seen in traditional social stereotypes as being gentle and caring, and people take it for granted that they should take more responsibility for taking care of the family. In higher education, if college students subscribe to social stereotypes, they fall into a fixed pattern and limit their own future. Subject separation is a notable case in which men and women are concentrated in the fields that society thinks they should be engaged in, giving rise to the problem of occupation segregation referred to below.

Second, assimilation of higher education refers to the homogenization of higher educational institutions. It is the phenomenon that schools tend to have the same educational goals, modes and subject settings in the development of higher education. From a macroscopic point of view, the essential reason for this phenomenon lies in the relatively single evaluation mode of higher education. In the process of evaluation, the evaluation subject measures the evaluation object with similar or the same standard. This kind of evaluation index emphasizes the benefit, has undoubtedly played an important role in speeding up the popularization of higher education.

The concept of "Universal access to higher education" proposed by Trow in 1973 divides higher education into three stages: elite higher education, mass higher education and universal higher education, with $15 \%$ and $50 \%$ of the gross enrollment rate of higher education as the dividing line [10]. Since the enrollment expansion of higher education in 1999, the gross enrollment rate in China has reached $15 \%$ in 2002, crossing the threshold of popularization. In 2015, it reached $40 \%$ [2]. In 2020, China's higher education has achieved $54.4 \%$, officially entering the stage of universalization of higher education. From elite higher education to universal higher education, China's transition time is only half that of the United States, shorter than most developed countries [1]. Under such conditions, the assimilation of higher education brings hidden dangers. Specifically, it is that the diversity of universities enriches the domestic education. If everything is converging to be the same, education has lost its vitality. From other perspectives, in order to transition to a comprehensive university, some universities blindly set up disciplines and majors, ignoring their own teachers and professional background, which is likely to affect the quality of education and lead to the waste of teaching resources. As for the convergence of students' training modes, it is possible to blur the dividing line between theoretical talents and applied talents, causing both of them to lose their advantages in their fields of job hunting.

\subsection{Origin of Assimilation}

Educational assimilation in China is originated from educational popularization since 1978 , which resulted in the increasing number of institutions and higher educational students.

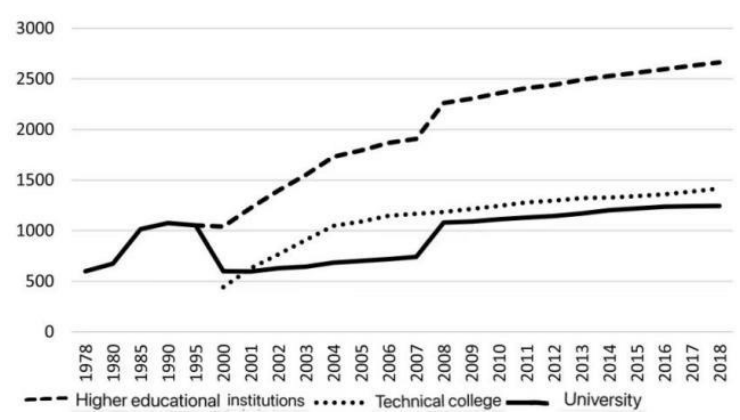

Figure 1: The number of higher education institutions from 1978 to 2018, sourced from educational statistics yearbook of China [11] 


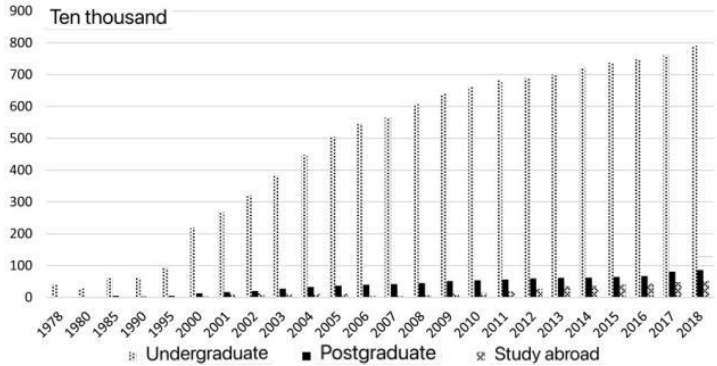

Figure 2: The number of higher educational students from 1978 to 2018, sourced from educational statistics yearbook of China [11]

Figure 1 indicated that the number of institutions of Chinese higher education rose from 598 in 1978 to 2663 in 2018. The number of students increased accordingly from 42,000 to 790 million (see Figure 2).

According to the data above, school assimilation is an inevitable stage in education popularization, which existed based on the position of schools and special system of higher education in China [12]. There are following reasons to cause school assimilation.

First of all, under the temptation of profits, schools always pursue the standard of key schools blindly and imitate other universities during its process of development, which take importance on quantity instead of the quality of teaching and talents. In addition, schools are compelled to assimilate to the key schools for they need to compete for the students who highly value the rank of schools. Then, more normal universities become similar to the other key schools on their mechanism and teaching content, but lose own culture and characteristic.

Second reason is the improper allocation of educational resources. College's desire plenty resources such as fund, teachers or equipment, but governments favor allocating resources to key schools called " 211 " and "985" in China which are priorities to be constructed. This policy forced normal schools raising their standards to close to the key schools and expanding enrollment to receive more resources. Moreover, schools are deprived of their characteristic and specialty by the one-dimension evaluation system, which pay attention to the quantity and number and use the same standard to evaluate universities from different regions. As a result, these oneside and incomplete mechanism advance the process of school assimilation.

Consequently, educational assimilation caused by less experience of schools, which tended to imitate other key schools to improve their competition to get more funds, enrollment and resources to develop their own comprehensive ability.

\subsection{Impact on Students}

Students are affected by assimilation in different aspects such as ability and education opportunity. This part will analyze how school assimilation can influence students, especially female students from three factors.

\subsubsection{Expanding Female Student Enrollment}

As the paper said above, school assimilation is the essential stage in the process of education popularization, which means school assimilation will offer more chances to help more female enter the field of higher education.

The expansion of higher education provides more chances for female students to accept education. The number of female students also raised year by year, from 268,000 in 1978 to 162.296 million in 2018 , and it still raising during recent years (illustrated in Figure 3).

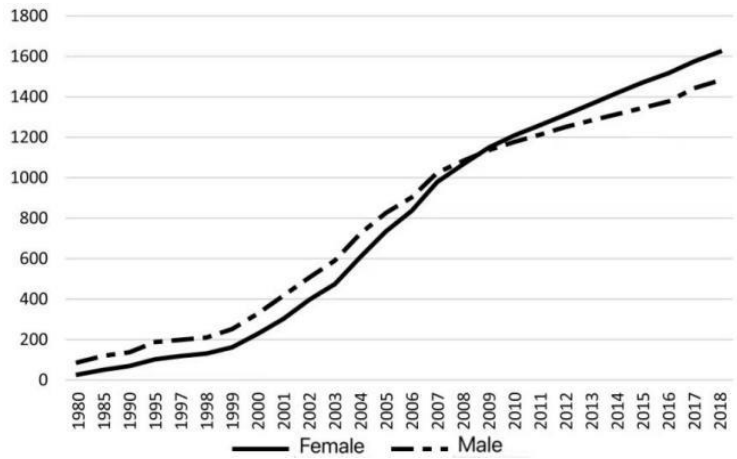

Figure 3: The number of the enrollment of male and female from 1980 to 2018, sourced from Educational statistics yearbook of China [11]

With the expansion of the number of institutions, and the rate of enrollments, the standards for receiving higher education for women decreased, and their period of education has been prolonged at the same time, which is the efficient method to improve women's education level and complete female capital accumulation. Such act effectively alleviates education inequality. Otherwise, female students lack the chances to receive education because of their duty as a women based on the traditional concept, and the ignorance of their parents.

\subsubsection{Subjects Separation}

Higher educational assimilation embodies subject separation on female and male students, which means men or women choose appropriate subject or major. Subject separation in light of gender. According to the data in 2018, female and male students always have different choice in subject and major. Male students tend to choose Science and Engineering such as Mechanism Design, Manufacturing and Automation, which the rate of male students have been over $70 \%$, but female students prefer to choose Humanities and Social Sciences such as Literature, Education and so on. For example, there are only one male student who majors in Political Science and Administration in the University of International Business and Economics (Beijing) [13]. 
It's clear that the rate of gender in some majors of institutions is extremely imbalanced, which also can be called subject separation. There are two reasons to cause this phenomenon. First, the choice of subject and major depends on the social stereotype and physical difference between male and female. Female's physical weakness and traditional social thinking which pursue steady life and need more time to take care their family. Therefore, they prefer to choose a kind of steady and dignity major, and Humanities and Social Science is the best choice. However, men are in opposite, they have better physical condition, flexible mind, and the heavy responsible to raise a family, hence the Science and Engineering major are fixed to men. Another reason is there is a common concept in the job market that "men is more important than women", which exacerbates gender imbalance. Moreover, in some field which proper to the women, men as a scarce resource, men are more dominant and have priority position than women [14]

Higher educational assimilation caused subject separation, which hindered women's equal participation in social production.

\subsubsection{Weakening Innovation and Creativity}

School assimilation may cultivate students with less innovation and creativity by many inferior paper and meaningless theoretical lesson.

Schools encourage students to do more research to get funds. Nonetheless, whether the paper, research topic, or scientific research project, there is a common phenomenon of blindly pursuing quantity of research and ignoring the quality. Moreover, the scores are the only way to evaluate the quality of thesis and the ability of students. As a consequence, there are few forwardlooking, practical and innovative research create by students, which will lead to the low efficiency and less innovation of students.

In China, schools attach more importance on the theoretical lessons instead of practice and technique lessons under the school's assimilation, which is an unspoken rules that test scores is the main standard to evaluate a students' ability. Therefore, more repeated professional settings and more theoretical lessons existed, which made education meaningless and more students lack experience, skills, initiative and adaptability to the job market after they graduated. Thus, there are more students who can only get high scores by taking test or writing papers, but lack of experience and practical ability.

In a word, schools' assimilation may produce students with lower quality, less innovation, less experience and practical ability.

\section{WOMEN'S TREATMENT IN CAREER}

\subsection{Gender Discrimination in Career}

In today's society, talent people have become the first productive force of social development. Thanks to the expansion of the scale of higher education, female talent resources are constantly developing and have become an important factor of social development. However, women in the workplace face more discrimination than men. Women's physical characteristics, psychological characteristics, thinking patterns, social stereotypes, as well as the role they play in the family, all lead to unfair treatment of career women.

At present, the gender discrimination of career women is mainly reflected in job opportunity and disparate treatment. In terms of job opportunity, although the government has introduced corresponding measures to protect the rights and interests of women in the workplace, employers still prefer to employ men in practice. A research report released by the National Academy of Development and Strategy at Renmin University of China bears this out, it noted that male candidates were invited for interviews 1.42 times more often than female candidates with the same resume background. In terms of employment treatment, gender pay gap summarizes the phenomenon that women earn less than men due to discrimination when their educational background, work and experience are the same as men's. Generally speaking, employers' discrimination against female labor force will be expressed through "unequal pay for equal work". Compared with men, it is more difficult for women to get close to core positions in the workplace. Such uneven distribution of economic resources leads to the salary gap and further causes the difficulty of promotion for women in the workplace.

\subsection{The Effect of Educational Assimilation on Career Women}

The following sections attempts to explain the causes that leads to gender gap in employment from education popularization, subject separation, and exam-oriented education.

\subsubsection{The Effect of Education Popularization}

The research of Changan Li and Zhijiao Yang shows that the expansion of higher education greatly increases the number of students in higher education, thus increasing the number female students enrolled in higher education. This fact also provides a basis for analyzing the effect of the popularization of higher education on career women.

A variety of studies have pointed out that with the expansion of education, the problem of unemployment 
among college students is more obvious than before [15]. Some studies even show that unemployment is an inevitable phenomenon in the popularization of higher education. Both India and South Korea experienced a decline in the employment rate of graduates during the expansion of higher education. The employment rate of graduates of Japanese universities also began to decline year by year from $80.9 \%$ in 1991 , and has been hovering between $60 \%$ and $70 \%$ since 1995 [14]. The reasons for unemployment are mainly based on two factors: first, the popularity of higher education brings more college graduates; second, if there is no major adjustment of industrial structure, the absorption capacity of college graduates in the labor market will not increase significantly $[16,17]$. The combined action of these two factors intensifies the competition for jobs, leading to an oversupply in the labor market and a rise in the unemployment rate of college students.

In this context, the education popularization is likely to affect career women through two mechanisms. First, the expansion of higher education has provided more college graduates, resulting in a market environment where supply exceeds demand. In this case, employers have more choices, and this mechanism is likely to intensify discrimination against career women when employers tend to hire men from the start.

Second, with the expansion of higher education, more and more women have gained the opportunity to receive higher education. For the first time in 2010, the proportion of women in higher education opportunities exceeded that of men [12]. Meanwhile, women are beginning to take the lead in the academic competition at all levels of education. If this advantage of human capital can be fully accumulated, more women will enter highwage industries and positions than before, which will play a positive role in bridging the gender wage gap and gender discrimination in the workplace.

Studies show that in the current market, the influence of the first mechanism is gradually diminishing [18]. To some extent, the expansion of higher education has intensified the discrimination against women in the labor market and led to the rise of gender wage gap. However, the rate of increase in the gender wage gap is falling, which will cause the gap in total income to gradually stop widening.

\subsubsection{The Effect of Subject Separation}

Subject separation in higher education will inevitably lead to occupation segregation in the labor market. Occupation segregation refers to the concentration of different genders in different industries and positions due to social factors, which is also one of the main manifestations of gender discrimination in the labor market. Studies have shown that the field of study in higher education is closely related to an individual's future career choice. Professions with higher economic demands, such as medicine, law and engineering, will earn higher incomes than those in education, art or humanities [19]. As mentioned above, subject separation leads to the concentration of men and women in different majors. Most men majored in science and engineering, while most women majored in literature, economics or education. This will further lead to the fact that women tend to be concentrated in some auxiliary and highly substitutable occupations in the labor market, such as cashiers or clerks, while men are able to engage in occupations with high technical content and difficult professional level, e.g., engineers and technicians. As a result, gender differences spread in the order of education, occupation, income, and women's status [14]. Subject separation leads to occupation segregation, which affects career women.

Furthermore, subject separation will lead to women's disadvantage in the labor market. Studies have shown that the choice of field of study can explain $25 \%$ to $50 \%$ of the income gap [20]. Owing to subject separation in the assimilation of higher education, women are concentrated in low-skilled and easily replaceable industries, which will affect highly educated women and reduce their salary expectations. On the other hand, when a large number of women are restricted to a relatively narrow range of career choices, their wages are more likely to fall. For example, in the education industry, the number of female teachers is too much, which is not conducive to the growth of teenagers, so the industry will adopt the policy of hiring male teachers with high salaries to balance.

In general, subject separation limits the employment scope of women and further affects their position in the labor market, which to some extent leads to the situation of difficult employment and low income of women in the workplace.

\subsubsection{The Effect of Exam-oriented Education}

The decline in teaching quality caused by school assimilation also affects career women. The failure of teacher resources to keep up with the scale of education and the single teaching model has led to the decline of students' practical ability. It is foreseeable that with the popularization of higher education in China, the influx of college graduates into the market will devalue the diploma. For employers, the lower quality of graduates will lead to higher training costs. As the cost of employment rises, the disadvantage of female job seekers will become more obvious, as it is traditionally believed that women are at higher risk of leaving their jobs for family reasons than men.

\section{CONCLUSION}

Prior to commencing the analysis, this paper attempted to help authors gain a better understanding 
about how the influence of educational assimilation affects career women. Combined with other excellent thesis, we address new theoretical perspectives of the connection between educational assimilation and gender discrimination in workplace.

According to the analysis, educational assimilation has close connection to the development of career women. This article discussed the definition of educational analysis, which means similar thinking, values and self-positioning and explains it from two aspects in detail: social stereotypes and homogenization. Then, this paper does the research about the origin of educational assimilation. Insight into the perspectives of definition, origin of assimilation and gender discrimination, this paper found that educational assimilation had pros and cons. Firstly, education popularization made women become more competitive for a job than before. Secondly, educational assimilation may cause subject separation, which may decide different genders' choice about what they learn and what types of job they do in the future, and their salary will depend on the position of jobs in the market indirectly. The last one is exam-oriented education, which is an unavoidable stage of educational assimilation, will reduce graduates' quality and innovation, which may cause career women in a more adverse position.

However, educational assimilation is not the only element to the gender discrimination. There are more factors such as history and family. Moreover, such unequal treatment between different genders still exist to date and gradually become a more popular topic among the people. On this basis, future research should be conducted to investigate how the other factors affects cause gender discrimination in workplace and analyze in detail. Meanwhile, not just limited in the theoretical aspect, the research also can provide some efficient and practicable guideline to improve women's treatment in their career, which can be implemented to improve the position of women tangibly.

\section{REFERENCES}

[1] Zhong Binglin, WANG Xinfeng, Opportunities, Challenges and Prospects: Universal Access of Higher Education in China, in: China Higher Education Research 2019(08):713.DOI:10.16298/j.cnki.1004-3667.2019.08.02

[2] Wang Xiaomei, Treating the problem of homogenization of universities in China rationally, in: Wenhui Newspaper, 2016. DOI:10.28814/n.cnki.nwehu.2016.003149

[3] Zhang Song, Zhang Guodong, Research on Latedevelopment Advantage of China's Higher Education in the Background of Global Education Homogenization, in: Forum on Contemporary
Education, NO.4, 2016. DOI:10.13694/j.cnki.ddjylt.2016.04.001

[4] Liu Qingjing, Yu Changzhi, Causes and Countermeasures of Excessive Homogeneity of Higher Education in China, in: Higher Agricultural Education,2011-5,5:9-12. DOI 10.13839/j.cnki.hae.2011.05.007

[5] Song Di, Research on the return rate of higher education from the perspective of gender difference, in: Market Weekly. 2021,34(01)

[6] Su Jiamin, Influences of Organization Gender Prejudice on the Career Development of Female Managers, in: University of Electronic Science and Technology of China, 2018

[7] Li Jianing, Research on the Relationship between Gender Role and Occupational Gender Stereotype and Its Intervention, in: Northwest University, 2020. DOI: 10.27405/d.cnki.gxbdu.2020.000007

[8] Yang Juhua, "Double Penalty of Gender and Motherhood" and Female Labor Force Participation, in: Population Research, vol.43, No.1, Jan.2019

[9] Boss Zhipin Research Institute, China workplace Gender Gap report, 2021

[10] Zhang Zhenyu, Long Yuejun, Unscrambling and Developing the Stage Theory of Martin Trow's Higher Education Development, in: Meitan Higher Education, vol.25, No.4, July.2007. DOI:10.16126/j.cnki.32-1365/g4.2007.04.011

[11] Chinese Ministry of Education, Educational statistics yearbook of China, 2018

[12] Xue Lian, The Causes and Countermeasures of Assimilation in Chinese Universities. Jiangsu Society of Higher Education, 2013

[13] Li Changan, Yang Zhijiao. Differences of Gender Structure and Gender Equality in Higher Education. Review of Higher Education, 2020(6): 8-17

[14] Cheng Jinkuan, Yan Tiantian. Dual Gender Disparities in Higher Education Research as a Discipline and a Profession: Towards a Theoretical Analysis. Modern University Education. 2015(3): 23

[15] He Yiming, A Study on the Effect of the Expansion of Higher Education on Employment and Wage in China, in: Jinan University, 2007

[16] Li Fengliang, Ding Xiaohao, A Test of Educational Contribution to Augmenting Productivity in China, in: Tsinghua Journal of Education, vol.24, No.5, Oct.2003 
[17] Yue Changjun, Wen Dongmao, Ding Xiaohao, Job hunting and Initial Salary: An Empirical Analysis of Employment Competitiveness of College Graduates, in: Management World, No.11, 2004. DOI: 10.19744/j.cnki.11-1235/f.2004.11.008

[18] Ouyang Renfei, Meng Dahu, Yang Juan, Higher Education Expansion and the Evolution of Gender Wage Gap among College Graduates: An Empirical Analysis Based on CHIPs2002-2013 data, in: Tsinghua Journal of Education, vol38, No.3,
May.2017. DOI : $\quad 10.14138 / j .1001-$ 4519.2017.03.009810

[19] Whitehead, J. M. Sex Stereotypes, Gender Identity and Subject Choice at A-level, in: Education Reserch, Vol 38, 1996, pp.147-160. DOI: $10.1080 / 0013188960380203$

[20] Donna Bobbitt-Zeher, The Gender Income Gap and the Role of Education, in: Sociology of Education, Vol 80, Issue 1. 2007. pp 1-22. DOI: $10.1177 / 003804070708000101$ 